\title{
Data of hydraulic properties of North East and North Central German soils
}

\author{
U. Schindler and L. Müller \\ Leibniz Centre for Agricultural Landscape Research (ZALF), Institute of Landscape Hydrology, \\ Eberswalder Str. 84, 15374 Müncheberg, Germany
}

Received: 29 April 2010 - Published in Earth Syst. Sci. Data Discuss.: 11 May 2010

Revised: 8 July 2010 - Accepted: 12 July 2010 - Published: 15 July 2010

\begin{abstract}
The paper presents a data base of soil physical and hydrological properties of North East and North Central German soils. Included are measured data of the soil water retention curve and the unsaturated hydraulic conductivity function. Information on geo-reference, soil type and horizon are given. Soil hydraulic functions were measured with the evaporation method. The applied measurement technique is described and information to actual innovations and advanced technology is given. Additional soil physical data like particle size distribution, dry bulk density, organic matter content and other variables are presented. The data base includes original measurement results of 278 organic and of 497 mineral soil samples from 103 sites. The mineral soils cover a wide range of texture classes and dry bulk densities. The organic soils and samples represent different states of decomposition and mineralization. Furthermore hydraulic functions are included of soils anthropogenically altered by deep plough sand covering measures.
\end{abstract}

\section{Introduction}

Knowledge of soil hydraulic functions is required for various hydrological and plant physiological studies. During the last decades numerous measurement procedures have been developed. Currently a broad array of methods exists for the determination of soil hydraulic properties in the field or in the laboratory (Klute and Dirksen, 1986; Dane and Hopmans, 2002; Nimmo et al., 2002; Arya, 2002). The evaporation method is a frequently used procedure for measuring hydraulic functions of unsaturated soil samples in the laboratory (Wind, 1966; Becher, 1970; Schindler, 1980; Wendroth et al., 1993; Halbertsma, 1996; Bertuzzi et al., 1999; Arya, 2002). The method allows an accurate characterization of the water retention properties of the porous system, between saturation and the measurement limit of tensiometers, and of the unsaturated hydraulic conductivity in the range where significant hydraulic gradients occur in the sample (Schindler and Müller, 2006; Peters and Durner, 2008). The method of Schindler (1980) is a simplified setup of the evaporation method presented by Wind (1968). Only the total soil sample weight and tensions at two height levels are recorded at sev- eral times as the basis for quantifying the hydraulic functions. Peters and Durner (2008) showed that despite the larger spatial distance of the tensiometers, effects of spatial and temporal nonlinearity of the soil wetness distribution are negligible in the data evaluation and that the method leads to precise and unbiased results, provided that the usual assumption of water flow according to Richards' equation, with instantaneous local equilibrium between water content and matric pressure, is valid (Durner and Flühler, 2005).

In the period between 1976 and 1992 soil hydrological properties - water retention curve and unsaturated hydraulic conductivity function - of 775 soil samples were measured with the evaporation method. The samples were collected from 103 sites located in North East and North Central Germany. The data base includes the soil hydrological properties and additional information to the geo reference, the soil type and horizon, the particle size distribution, the dry bulk density and other parameters and is available at the ZALF homepage (mineral soils: doi:10.4228/ZALF.1977.164; organic soils: doi:10.4228/ZALF.1978.165). Information on the applied methodology and measurement techniques is given in the following.

Correspondence to: U. Schindler

(uschindler@zalf.de) 


\section{Materials and methods}

\subsection{Soils and sites}

Measurements of the water retention curve and the unsaturated hydraulic conductivity function were carried out in the laboratory with the evaporation method (Schindler, 1980). The 497 mineral soil samples cover a wide range of texture classes (AG Boden, KA4 1994) (Fig. 1) and dry bulk densities. The organic matter content ranged between 0 and maximum about $5 \%$. The structure of the soils was assigned according to FAO guidelines (1990) to 5 classes: SG - single grain, GR - granular, PR - prismatic, PS - subangular prismatic, MA - massive. The 278 organic soils contain peat samples (organic matter content $>30 \%$ ) of different grades of decomposition and mineralization, several muddy substrates, as well as clay and sand soils rich in humus (organic matter content $>10 \%$ ) (Table 1). Additionally to the soil hydrological properties, the particle size distribution, dry bulk density, organic matter content and other parameters were measured. However, most fen sites are underlain by sand. These mineral samples are included in the database of organic soils, too. Different pedogenetically altered soil types of deep and shallow fens, with and without sapric horizons (mud, F: Fc calceric mud, Fs - sandy mud, Ft - clayey mud, Fi - organic mud) in the profile were considered. The following soil types were studied: earthyfied fen (Erdfen), weakly moorshyfied fen (Fenmulm) and moorsh (Mulm) with the horizons (following Succow and Joosten, 2001).

- nH: Pedogenetically almost unmodified peat below the water table.

- nHa: Peat subsoil horizon with segregation structure as a consequence of swelling and shrinking.

- nHv: Earthyfied peat topsoil horizon, crumbles and small-polyhedric aggregates.

- nHvm: Weakly moorshyfied topsoil horizon, intermediate stage between $\mathrm{nHv}$ and $\mathrm{nHm}$

- nHm: Moorsh topsoil horizon, small aggregates, powder-like under dry conditions, smeary under wet conditions

In addition, half-fen soils (Aa) with organic matter content lower than 30\%, sand covered fens (yYAp), as well as deepploughed sites (R) were investigated (Schindler et al., 1999). At the deep-ploughed sites we analyzed the A horizon (RApmixture of sand and a small amount of peat) underlain by the sand (RGo) and peat $(\mathrm{RnH})$ plough section.

\subsection{Data base}

The data (raw data) are collected in the soil hydrological data base of the Institute of Landscape Hydrology of the ZALF at

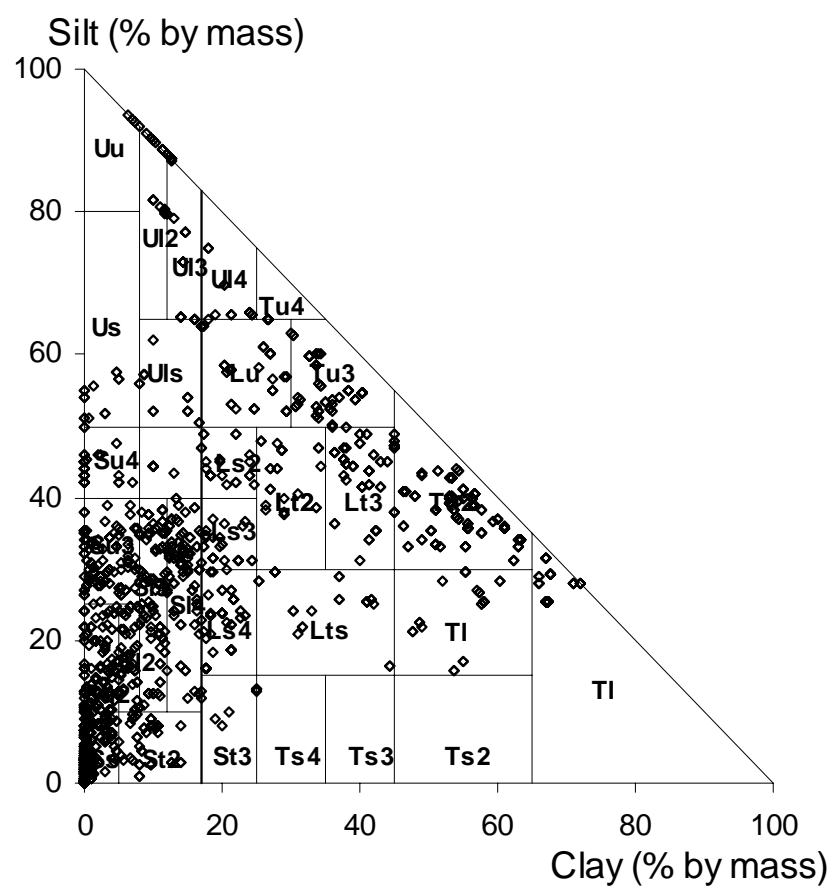

Figure 1. Distribution of texture classes according to German classification (Arbeitsgruppe Boden, KA4, 1994) of the investigated soils. Warning: There is a mismatch between the German PSD system and the internationally frequently used FAO/USDA system.

Müncheberg. The structure of the data base is the same as in the HYPRES database (Wösten et al., 1999). Table 1 gives an overview of the data base content.

\subsection{Measurement of soil hydraulic properties with the evaporation method (Schindler, 1980)}

Intact soil cores are taken in stainless steel cylinders $\left(250 \mathrm{~cm}^{3}\right.$ volume, $6 \mathrm{~cm}$ height) with a sharpened leading edge to minimize soil disturbance during insertion. Two tensiometers are installed horizontally at depths of 1.5 and $4.5 \mathrm{~cm}$ above the bottom of the core. Cores were slowly saturated in the laboratory by placing them in a pan of water. After saturation, the sample is sealed at the bottom and placed on a balance. Its surface remains open to evaporation. Tension $(\Psi)$ and sample mass $(m)$ are measured at time intervals. The measurement interval of both sample mass and tension varies, depending on soil material and evaporation rate, between 10 min (clay soils and sand near the end of measurement, when the hydraulic gradient increases rapidly) and $4 \mathrm{~h}$ (sand soils at the beginning of measurement, as long as the hydraulic gradient is small). The measurement is finished when the upper tensiometer reached its tension limit. Tension is measured with mercury tensiometers (measurement range $0<h<70 \mathrm{kPa}$, measurement accuracy $0.1 \mathrm{kPa}$ ). The mean hydraulic gradient $\left(i_{m}\right)$ is calculated on the basis of the tension values in the time interval. The flux $(v)$ is derived 
Table 1. Data base content and structure.

\begin{tabular}{|c|c|}
\hline Basis data & Site name \\
\hline & $\begin{array}{l}\text { Soil type acc. to FAO guidelines } \\
\text { Local soil type (KA4) } \\
\text { Geo reference (ETRS89) } \\
\text { Sampling depth } \\
\text { Site description (land use, region, geological origin) } \\
\text { Sampling date } \\
\text { Average annual rain fall } \\
\text { Average temperature in January } \\
\text { Average temperature in July } \\
\text { Number of horizons }\end{array}$ \\
\hline Soil properties & $\begin{array}{l}\text { Site name } \\
\text { Geo reference } \\
\text { Horizon } \\
\text { Soil structure } \\
\text { Dry bulk density }\left(\mathrm{cm}^{3} \mathrm{~cm}^{-3}\right) \\
\text { Organic matter content }(\%) \\
\text { Ash content }(\%) \\
\text { Saturated hydraulic conductivity }\left(\mathrm{cm} \mathrm{d}^{-1}\right)\end{array}$ \\
\hline Particle size distribution (PSD) & $\begin{array}{l}\text { Site name } \\
\text { Geo reference } \\
\text { Horizon } \\
\text { Sample number } \\
\text { Percentage of particle classes }(\mathrm{mm}) \\
\text { Clay: } 0.002 \\
\text { Fine silt: } 0.0063 \\
\text { Medium silt: } 0.02 \\
\text { Coarse silt: } 0.063 \\
\text { Fine sand: } 0.2 \\
\text { Medium sand: } 0.63 \\
\text { Coarse sand: } 2\end{array}$ \\
\hline Soil water retention function & $\begin{array}{l}\text { Site name } \\
\text { Geo reference } \\
\text { Horizon } \\
\text { Sample number } \\
\text { Pair of values of water content }\left(\mathrm{cm}^{3} \mathrm{~cm}^{-3}\right) \text { and tension }(\mathrm{hPa})\end{array}$ \\
\hline Unsaturated hydraulic conductivity & $\begin{array}{l}\text { Site name } \\
\text { Geo reference } \\
\text { Horizon } \\
\text { Sample number } \\
\text { Pair of values of tension }(\mathrm{hPa}) \text { and hydraulic conductivity }\left(\mathrm{cm} \mathrm{d}^{-1}\right)\end{array}$ \\
\hline
\end{tabular}

Soil and site description was done according to Arbeitsgruppe Boden (KA4, 1994), bold face are fields linking between tables.

from the soil water volume difference $\Delta V$ (assuming $1 \mathrm{~cm}^{3}$ of water $=1 \mathrm{~g}$ ) per surface area $(A)$ and time unit $(\Delta t)$. Single points of the water retention curve are calculated on the basis of the water loss per volume of the sample at time $t$ and the tension averaged over the sample at that time.
The hydraulic conductivity $(K)$ is calculated according to Darcy-Buckingham's law (Eq. 1).

$K(\bar{\Psi})=\frac{\Delta V}{2 A \cdot \Delta t \cdot i_{m}}$

where $\bar{\Psi}$ is the mean tension averaged over the upper tensiometer at position $z_{1}(4.5 \mathrm{~cm}$ above bottom) and the lower tensiometer at position $z_{2}(1.5 \mathrm{~cm}$ above bottom), $\Delta t$ is the 

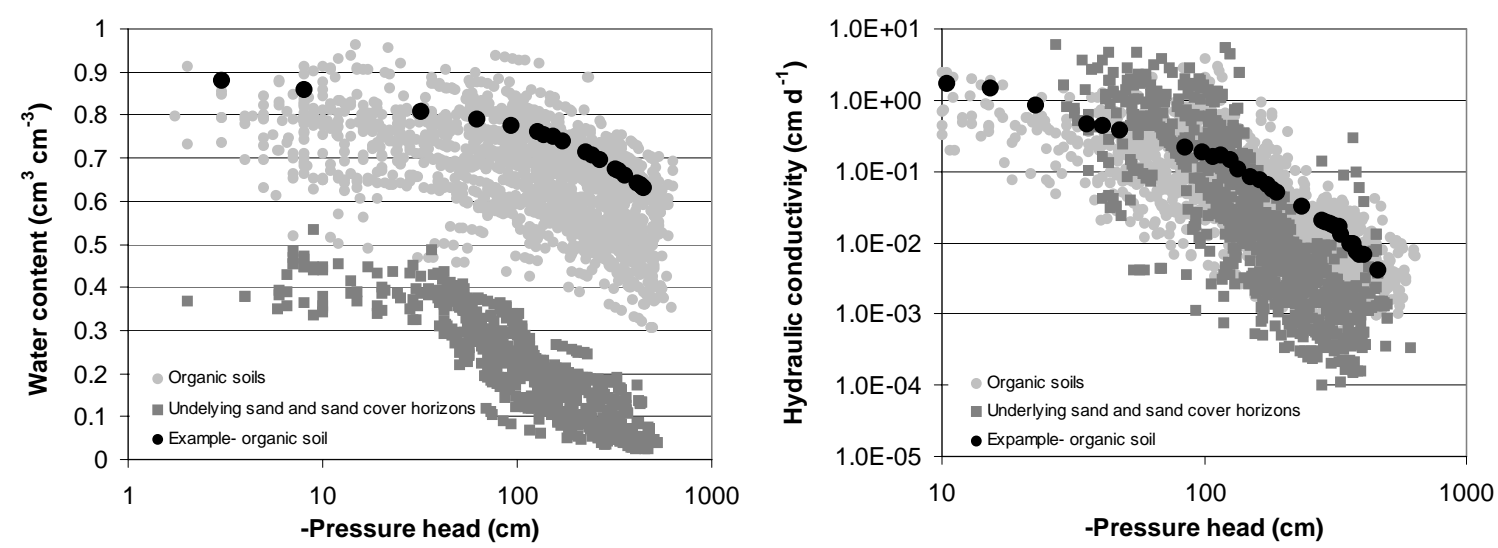

Figure 2. Data range of organic soils, underlying sand and sand cover horizons, and a pair of measured hydraulic functions.

time interval, $\Delta V$ is the total water volume evaporated from the complete sample (equal to sample mass difference, $\Delta m$, in the given time interval), $A$ is the cross sectional area of the sample, and $i_{m}$ is the mean hydraulic gradient effective in the time interval, given by:

$i_{m}=\frac{1}{2} \cdot\left(\frac{\Psi_{t 1 \text {,upper }}-\Psi_{t 1, \text { lower }}}{\Delta z}+\frac{\Psi_{t 2, \text { upper }}-\Psi_{t 2 \text { lower }}}{\Delta z}\right)-1$

where $\Psi_{t \text {,upper,lower }}$ indicate the tension values of the upper and lower tensiometers at time $t$, and $\Delta z$ is the vertical distance of the tensiometers from each other. At the end of the measurement, the amount of water that remained in the sample is determined by drying in an $105^{\circ} \mathrm{C}$ oven and weighting the dry sample.

The assumptions for the validity of Eq. (1) are:

i) "quasi steady state" conditions, which means that flux and hydraulic gradient are approximately constant over the time interval.

ii) linear decreasing water content over the sample height in the time interval. Accordingly, the flux through the measured layer (half of the total flux) can be calculated from the soil water volume difference in the time interval. Results by Peters and Durner (2008) confirmed the validity of these assumptions.

The initial water content is determined using the sum of the water content (loss by evaporation plus the residual water content after the last measurement) and the volume of the core. Dry bulk density is derived from dry soil mass divided by core volume. For this reason the volume of the tensiometer holes $\left(1 \mathrm{~cm}^{3}\right)$ is subtracted from the core. The total measurement time is depending on the evaporation rate and the soil water content in the measurement range (tension between 0 and about $60 \mathrm{kPa}$ ) and varies between 3 days for clay soils and maximum 10 days for sand and peat soils. Figure 2 presents exemplarily the data range of measured hydraulic functions of the organic soils. Included are the range of hydraulic properties of the underlying sand of the fen sites and the sand cover horizons of the deep-ploughed sites, as well as an example of a pair of measured hydraulic functions, as obtained using the evaporation method.

\subsubsection{Advantages and disadvantages of the current evaporation method}

The main advantage of the evaporation method is the simultaneous quantification of both the water retention curve and the unsaturated hydraulic conductivity function. The method is robust, easy to handle, and the curves are accurately described by a multitude of measurements. The water retention function has a high resolution over the entire range from wet to dry conditions. The hydraulic conductivity function is well described in the drier part of the function. Uncertainties in tension measurement at the beginning of the experiment, however, can lead to uncertainties in the hydraulic gradient and the calculated hydraulic conductivities (Peters and Durner, 2008).

The main disadvantage is the limited measurement range between 0 and maximum $60 \mathrm{kPa}$ (average tension in the soil sample at the end of measurement). Due to sometimes short measuring intervals $(<1 \mathrm{~h})$, the demand on weighing accuracy is very high (at least $0.01 \mathrm{~g}$ ). In order to minimize weighing errors it is recommended to leave the sample on the balance during the entire measuring period. As a result, each sample needs its own balance, and therefore the equipment required is rather cost intensive. This situation cannot be remedied by applying automatic sample changers.

\subsubsection{Innovations (not yet effective for the published soil physical data base)}

1. The use of evaporation functions for quantifying the evaporative water loss enables extending the weighing intervals and reduces the requirement on the weighing accuracy. This reduces costs for the measuring equipment and increases the effectiveness of the 

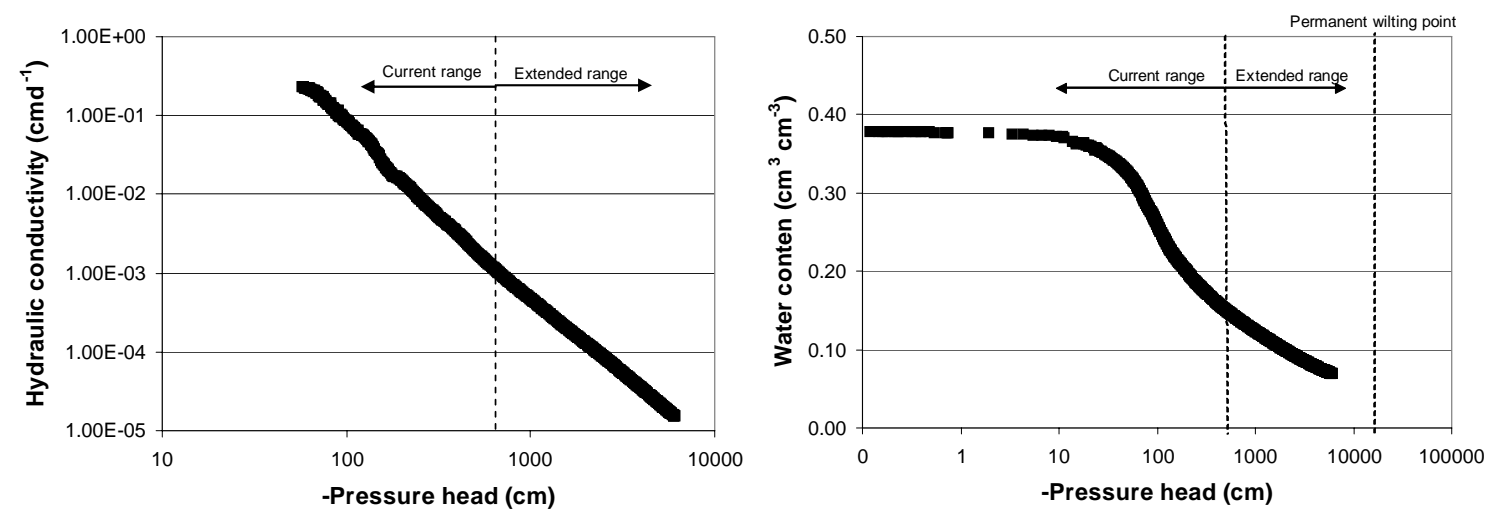

Figure 3. Extended hydraulic functions measured with the evaporation method. Sandy loam, Dedelow, Uckermark (Germany).

method while maintaining the same quality of unsaturated hydraulic conductivity and water retention functions (Schindler et al., 2006).

2. Applying new cavitation tensiometers and using the airentry pressure of the tensiometer's porous ceramic cup as additional defined tension value allows the quantification of hydraulic functions up to close to the wilting point (Fig. 3, Schindler et al., 2010a, b). Depending on the evaporation rate and the evaporative water loss during the evaporation measurement, the entire measurement time varies between 3 days for clay soils and maximum 10 days for sand and peat soils. Compared with the mainly used techniques (water retention curve: sandbox, kaolinite box and pressure plate extractor; unsaturated hydraulic conductivity function: multi-step outflow method), the evaporation method is cost and time saving.

\subsection{Methods to determine other physical properties}

\subsubsection{Particle size analyzes}

The particle size distribution is an important basic soil physical variable for characterizing and classifying soils. Particlesize measurements took place using the gravitational sedimentation (pipette method) according to Gee and Or (2008). It relies on the relationship between settling velocity and particle diameter at a given depth.

Two conditions need to be met before running the measurements:

1. Disintegration of the soil material and

2. a solution free of organic carbon, calcium and other salts.

Pretreatment of samples to enhance the separation or dispersion of aggregates is a key step in particle-size measurement and is generally recommended since many soils contain aggregates that are not readily dispersed (Gee and Or, 2002).
Organic carbon was destroyed by cooking in hydrogen peroxide $\left(\mathrm{H}_{2} \mathrm{O}_{2}\right)$. Dispersion occurred by shaking in sodium pyrophosphate $\left(\mathrm{Na}_{4} \mathrm{P}_{2} \mathrm{O}_{7}\right)$. Analyzed particle classes were: clay $(<0.002 \mathrm{~mm})$, fine silt $(0.002-0.0063 \mathrm{~mm})$, medium silt $(0.0063-0.02 \mathrm{~mm})$, fine silt $(0.02-0.063 \mathrm{~mm})$. The sand fraction, fine sand $(0.063-0.2 \mathrm{~mm})$, medium sand $(0.2-$ $0.63 \mathrm{~mm})$, and coarse sand $(0.63-2 \mathrm{~mm})$, was analyzed by wet sieving of the disperse solution. Warning: There is a mismatch between the German PSD (Particle-Size-Distribution) system and the internationally frequently used FAO/USDA system. However, the provided data conforms with the ISSS PSD system. Interpolation techniques should be developed in future.

\subsubsection{Soil organic matter content and ash content}

The soil organic matter content was analysed by dry combustion according to DIN ISO 10694 (1994), and calculated on the basis of:

soil organic matter content $=$ organic $\mathrm{C} \cdot 1.724$

The ash content was measured by combustion at $550{ }^{\circ} \mathrm{C}$ (DIN 19684 T3) related to the oven-dried soil sample (DIN ISO 11465).

\section{Conclusions}

The measurement of soil hydraulic properties like the water retention curve and the unsaturated hydraulic function is costly and time consuming. The presented soil physical data cover a wide range of North East and North Central German soils and sites. The data provided here allow improving soil-specific scientific investigations in an effective way and could be helpful for organizations and individuals dealing with practical applications like irrigation or soil and water management. 


\section{Data access}

The data of the mineral soils are published under doi:10.4228/ZALF.1977.164. The data set contains 497 soil samples covering a wide range of textures, bulk densities and organic matter contents. The data of the organic soils are published under doi:10.4228/ZALF.1978.165. The data set contains 278 soil samples that cover a wide range of soils with different degrees of decomposition and mineralization as well as wide ranges of bulk density and porosity.

Acknowledgements. We thank J. Pilz from the ZALF Landscape information system group, R. Dannowski from the Institute of Landscape Hydrology of the ZALF for helpful assistance, and the anonymous referees for their helpful comments, remarks and suggestions.

Edited by: N. Verhoest

\section{References}

Arbeitsgruppe Boden der Geologischen Landesämter und der Bundesanstalt für Geowissenschaften und Rohstoffe der Bundesrepublik Deutschland: Bodenkundliche Kartieranleitung, 4. Auflage, Hannover (als KA 4 zitiert), 1994.

Arya, L. M.: Wind and hot-air methods, in: Methods of soil analysis, Part 4, Physical methods, edited by: Dane, J. H. and Topp, G. C., SSSA Book Ser. 5, SSSA, Madison, WI, 916-926, 2002.

Becher, H. H.: Ein Verfahren zur Messung der ungesättigten Wasserleitfähigkeit, Z. Pflanzenernaehrung u. Bodenkd., 128, 112, 1970.

Bertuzzi, P. and Voltz, M.: The Wind method: A standard laboratory method adopted by the French INRA laboratories, Workshop Proceedings: The use of pedotransfer in soil hydrology research, 10-12 Oct., Orleans, France, 51-53, 1997.

Dane J. H. and Hopmans, J. W.: Pressure plate extractor, in: Methods of soil analysis, Part 4, Physical methods, edited by: Dane, J. H. and Topp, G. C., SSSA Book Ser. 5, SSSA, Madison, WI, 688-690, 2002.

DIN 19684: Bodenuntersuchungsverfahren im Landwirtschaftlichen Wasserbau - Chemische Laboruntersuchungen, 1977.

DIN ISO 11465: Bestimmung des Trockenrueckstandes und des Wassergehalts auf der Grundlage der Masse, 1996.

DIN ISO 10694: Bodenbeschaffenheit: Bestimmung des organischen Kohlenstoffgehaltes und des Gesamtkohlenstoffgehaltes nach trockener Verbrennung (Elementaranalyse), 1994.

Durner, W. and H. Flühler: Soil Hydraulic Properties, in: Encyclopedia of Hydrological Sciences, Chapter 74, edited by: Anderson, M. G. and McDonnell, J. J., John Wiley \& Sons Ltd., 1103-1120, 2006.
FAO: Guidelines for Soil Description, 3rd Edn., Rome, 1990.

Gee, G. W. and Or, D.: Particle-Size Analysis, in: Methods of soil analysis, Part 4, Physical methods, edited by: Dane, J. H. and Topp, G. C., SSSA Book Ser. 5, SSSA, Madison, WI, 255-293, 2002.

Halbertsma, J.: Wind's evaporation method, determination of the water retention characteristics and unsaturated hydraulic conductivity of soil samples. Possibilities, advantages and disadvantages, European Workshop on Advanced Methods to Determine Hydraulic Properties of Soils, Thurnau, Germany, 10-12 June 1996, Department of Hydrology, University of Bayreuth, 107 pp., 1996.

Nimmo, J. R., Perkins, K. S., and Lewis, A. M.: Steady-state centrifuge, in: Methods of soil analysis, Part 4, Physical methods, edited by: Dane, J. H. and Topp, G. C., SSSA Book Ser. 5, SSSA, Madison, WI, 903-916, 2002.

Peters, A. and Durner, W.: A simple model for describing hydraulic conductivity in unsaturated porous media accounting for film and capillary flow, Water Resour. Res., 44, W11417, doi:101029/2008WR007136, 2008.

Schindler, U.: Ein Schnellverfahren zur Messung der Wasserleitfähigkeit im teilgesättigten Boden an Stechzylinderproben, Arch. Acker- u. Pflanzenbau u. Bodenkd., Berlin, 24, 1-7, 1980.

Schindler, U., Müller, L., and Schäfer, W.: Entwicklung der physikalischen und hydrologischen Eigenschaften einer Tiefpflug- Sanddeckkultur, Z. Kulturtechnik und Landentwicklung, 40, 1-7, 1999.

Schindler, U. and Müller, L.: Simplifying the evaporation method for quantifying soil hydraulic properties, J. Plant Nutr. Soil Sc., 169, 623-629, 2006.

Schindler, U., Durner, W., von Unold, G., and Mueller, L.: Evaporation Method for Measuring Unsaturated Hydraulic Properties of Soils: Extending the Range, Soil Sci. Soc. Am. J., in press, doi:08.0358/sssaj2008.0358, 2010a.

Schindler, U., Durner, W., von Unold, G., Mueller, L., and Wieland, R.: The evaporation method - Extending the measurement range of soil hydraulic properties using the air-entry pressure of the ceramic cup, J. Plant Nutr. Soil Sc., in press, doi:10.1002/jpln.200900201, 2010 b.

Succow, M. and Joosten, H.: Landschaftsökologische Moorkunde, E. Schweizerbart'sche Verlagsbuchhandlung Stuttgart, 622 pp., 2001.

Wendroth, O., Ehlers, W., Hopmans, J. W., Kage, H., Halbertsma, J., and Wösten, J. H. M.: Reevaluation of the evaporation method for determining hydraulic functions in unsaturated soils, Soil Sci. Soc. Am. J., 57, 1436-1443, 1993.

Wind, G. P.: Capillary conductivity data estimated by a simple method, in: Proc. UNESCO/IASH Symp. Water in the unsaturated zone, Wageningen, The Netherlands, 181-191, 1968.

Wösten, J. H. M., Lilly, A., Nemes, A., and Le Bas, C.: Development and use of a database of hydraulic properties of European soils, Geoderma, 90, 169-185, 1999. 